GSA DATA REPOSITORY 2012325

\title{
Simpson and Castelltort
}

\section{SUPPLEMENTARY MATERIAL}

The response of flume-like alluvial channels is investigated in numerical simulations by solving the shallow water equations in one dimension coupled to a sandy non-cohesive river bed (details of the model can be found in Simpson and Castelltort, 2006). The mass and momentum conservation equations for the water-sediment mixture and the mass conservation equations, respectively, for sediment and bed material are:

$$
\begin{gathered}
\frac{\partial h}{\partial t}+\frac{\partial(h u)}{\partial x}=\frac{E-D}{1-\varphi} \\
\frac{\partial(h u)}{\partial t}+\frac{\partial}{\partial x}\left(h u^{2}+\frac{1}{2} g h^{2}\right)=-g h\left(\frac{\partial z}{\partial x}+S_{f}\right)+b_{x} \\
\frac{\partial(h c)}{\partial t}+\frac{\partial(h u c)}{\partial x}=E-D \\
\frac{\partial z}{\partial t}=\frac{D-E}{(1-\varphi)}
\end{gathered}
$$

where $t$ is time (s), $x$ is the streamwise coordinate $(\mathrm{m}), g$ is gravitational acceleration $\left(\mathrm{m} / \mathrm{s}^{2}\right), h$ is the water depth $(\mathrm{m}), u$ is the flow velocity $(\mathrm{m} / \mathrm{s}), c$ is the volumetric sediment concentration $\left(\mathrm{m}^{3} / \mathrm{m}^{3}\right), z$ is the bed elevation (m), $\varphi$ is the porosity of the bed sediment, $S_{f}$ is the friction slope, $E$ is the entrainment flux $(\mathrm{m} / \mathrm{s}), D$ is the deposition flux $(\mathrm{m} / \mathrm{s})$ and $b_{x}$ is a group of terms accounting for spatial variations in sediment concentration and momentum transfer due to sediment exchange between the flow and the erodible bed. To close these governing equations we employ Manning's relation for the friction slope:

$$
S_{f}=\frac{n^{2} u^{2}}{h^{4 / 3}}
$$

where $n$ is Manning's roughness coefficient, and the following empirical functions for the depositional and entrainment fluxes:

$$
\begin{gathered}
D=\omega\left(1-C_{a}\right)^{m} C_{a} \\
E=0.015 \frac{\left(\theta-\theta_{c}\right) u}{h d^{0.2}} \quad \text { when } \theta>\theta_{c} \\
E=0 \text { when } \quad \theta \leq \theta_{c}
\end{gathered}
$$

where $C_{a}(=2 c)$ is the near-bed sediment concentration, $m$ is an exponent, $\omega$ is the particle settling velocity $(\mathrm{m} / \mathrm{s})$ : 


$$
\omega=\sqrt{(13.95 v / d)^{2}+1.09 s g d}-13.95 v / d
$$

$v$ is the kinematic viscosity of water $\left(\mathrm{m}^{2} / \mathrm{s}\right), d$ is the sediment grain size $(\mathrm{m}), \rho_{s}$ and $\rho_{w}$ are the densities of sediment and water respectively $\left(\mathrm{kg} / \mathrm{m}^{3}\right), s\left(=\rho_{s} / \rho_{w}-1\right)$ is the submerged specific gravity of the sediment, $\theta\left(=u_{*} /(s g d)\right)$ is Shield's parameter, $u_{*}(=u \sqrt{n / 8})$ is the friction velocity and $\theta_{c}$ is the critical Shields parameter for initiation of sediment motion. This hyperbolic system of equations is solved with an explicit finite volume technique using the total-variation-diminishing (TVD) version of the second-order weighted average flux method (WAF) in conjunction with the HLLC approximate Riemann solver and the SUPERBEE limiter (Toro, 2001).

The model investigated is well known to accurately describe both highly transient and steady free surface flows involving sediment transport (Toro, 2001). Under conditions of steady uniform flow, it has been shown that the above equations can be reduced to a diffusion equation (e.g., Paola et al., 1992). The simplified diffusive model accurately describes channel aggradation and downcutting due to sediment overloading, but it is unlikely to be accurate for the conditions of this study where the flow conditions are both transient and nonuniform. Hence, we have retained the full nonlinear hyperbolic model to avoid introducing $a$ priori diffusive dampening of input signals. Nevertheless, our investigation is subject to various limitations. First, we assume the channel is one-dimensional and therefore ignore floodplain coupling and variations in channel width. Second, we don't explicitly include any bedload transport which, though usually a small part of the total transport load, is nevertheless important in determining channel morphology.

We consider a hypothetical river channel $100 \mathrm{~m}$ long with a low initial gradient $\left(10^{-5}\right.$ $\mathrm{m} / \mathrm{m}$ ) and uniform initial flow conditions. The spatial resolution in the horizontal direction was $1 \mathrm{~m}$ and typical time steps were on the order of 0.1 seconds (dynamic time-stepping was used). We impose the water flux and sediment concentration at the upstream boundary (left side in Fig. 1a) while at the downstream boundary we set the bed elevation to $0 \mathrm{~m}$ and fix the water depth to a constant value of $7.5 \mathrm{~cm}$ (flow is always subcritical). We initially run our numerical experiments with constant boundary conditions until the bed elevation reaches steady-state and the sediment outflux balances the sediment influx. We then perturb the model rivers with cyclic variability at the upstream boundary. In the case of water flux cycles, we impose a sinusoidal variation in $q_{w}\left(=h u=q_{o}+0.5 q_{o} \sin \frac{2 \pi t}{\lambda}\right.$ where $\lambda$ is the period (s) and $q_{o}\left(=0.0156 \mathrm{~m}^{2} / \mathrm{s}\right)$ is the mean water flux per unit width) while the inlet sediment concentration is held constant $(c=0.001)$. For sediment concentration cycles, we impose a sinusoidal variation in sediment concentration $c\left(=c_{o}+0.5 c_{o} \sin 2 \pi t / \lambda\right.$ where $\lambda$ is the period and $c_{o}(=0.001)$ is the mean sediment concentration) while the water flux is held constant $\left(q_{w}=0.0156 \mathrm{~m}^{2} / \mathrm{s}\right)$. Both scenarios introduce periodic variability (by a factor of 3) in the inlet sediment flux $q_{s}(=h u c)$ though the system response is by no means the same. Additional parameters adopted in our simulations are: $g=9.8 \mathrm{~m} / \mathrm{s}^{2}, d=0.5 \mathrm{~mm}, n=0.03, \mathrm{~m}$ $=2, \varphi=0.4, s=1.65, v=1.2 \times 10^{-6} \mathrm{~m}^{2} / \mathrm{s}, \theta_{c}=0.045$. 
Previous studies have recognized that the ability of rivers to transmit sediment pulses depends on the river response time - defined as the characteristic time required for a river to achieve equilibrium following a perturbation (Howard, 1982; Paola et al., 1992). In our models, the response time depends on both the magnitude and the sign of forcing. The time to change from an out-of-grade slope $S^{0}$ to an equilibrium slope $S^{\mathrm{e}}$ as a result of aggradation $\left(S^{o}<S^{e}\right)$ is

$$
\tau^{\uparrow}=\frac{\left(S^{e}-S^{o}\right) L^{2}(1-\varphi)}{2 q_{S}}
$$

where $L$ is the length of the river system $(m), q_{s}$ is the average sediment influx per unit width $\left(m^{2} s^{-1}\right)$ and $\varphi$ is the porosity of the sediment on the river bed (see also Howard, 1982). This equation bears a close resemblance to commonly employed relations based on scaling arguments for diffusion models (Castelltort and Van Den Driessche, 2003; Métivier and Gaudemer, 1999), though it is derived here on the basis of mass balance for a triangularshaped sediment wedge fed with sediment. The time to evolve from an out-of-grade slope $S^{o}$ to an equilibrium slope $S^{e}$ as a result of downcutting $\left(S^{o}>S^{e}\right)$ is

$$
\tau^{\downarrow}=\frac{\lambda}{2} \quad \text { (DR2) }
$$

where $\lambda$ is the period of the perturbation (s). In other words, downcutting of non-cohesive sediment is sufficiently rapid such that the adjustment time scale is limited by how fast forcing takes place (dictated by $\lambda$ ) rather than by sediment properties or fluvial processes.

\section{References Cited}

Castelltort, S., and Van Den Driessche, J., 2003, How plausible are high-frequency sediment supply-driven cycles in the stratigraphic record?: Sedimentary Geology, v. 157, p. 3-13, doi:10.1016/S0037-0738(03)00066-6.

Howard, A.D., 1982, Equilibrium and time scales in geomorphology: Application to sand-bed alluvial streams: Earth Surface Processes and Landforms, v. 7, p. 303-325, doi:10.1002/esp.3290070403.

Métivier, F., and Gaudemer, Y., 1999, Stability of output fluxes of large rivers in South and East Asia during the last 2 million years: Implications on floodplain processes: Basin Research, v. 11, p. 293-303, doi:10.1046/j.1365-2117.1999.00101.x.

Paola, C., Heller, P.L., and Angevine, C.L., 1992, The large-scale dynamics of grain-size variations in alluvial basins, 1: Theory: Basin Research, v. 4, p. 73-90, doi:10.1111/j.1365-2117.1992.tb00145.x.

Simpson, G. and Castelltort, S., 2006, A model for topographic evolution due to coupled surface water flow and sediment transport: Computers and Geosciences, v. 32, p. 16001614.

Toro, E.F. Shock-Capturing Methods for Free-Surface Shallow Flows (Wiley, New York, 2001). 